\title{
Dietary Iron Overload: Short- and Long-Term Effects on Cecal Morphometry in Growing Rats
}

\author{
Alexandre Rodrigues LOBO ${ }^{1}$, Maria Lucia COCATO ${ }^{1,2}$, \\ Lilian Rose Marques DE SÁ ${ }^{3}$ and Célia COLLI ${ }^{1, *}$ \\ ${ }^{1}$ Department of Food and Experimental Nutrition, Faculty of Pharmaceutical Sciences, \\ University of São Paulo, Brazil, Av. Prof. Lineu Prestes 580, Bloco 14, 05508 900, São Paulo, SP, Brazil \\ ${ }^{2}$ Anhembi Morumbi University, Brazil, Rua Dr. Almeida Lima 1134, 03164 000, São Paulo, SP, Brazil \\ ${ }^{3}$ Department of Pathology, Faculty of Veterinary Medicine and Zootechny, University of São Paulo, \\ Brazil, Av. Prof. Dr. Orlando Marques de Paiva, 87, 05508 000, São Paulo, SP, Brazil
}

(Received March 24, 2014)

\begin{abstract}
Summary In animal models, Fe overload is associated with organ oxidative stress and tissue injury. In this context, luminal Fe may affect the mucosal barrier and function or generate a pathological milieu in the intestine that triggers epithelial cell stress. Here, we hypothesized that increased liver Fe levels resulting from dietary Fe overload may be associated with architectural changes in the cecal mucosa. Weanling male Wistar rats $(n=7-10$ / group) were fed diets (modified from AIN-93G) containing adequate or supplemental Fe (approximately 10 times the recommended levels) for 4 and $12 \mathrm{wk}$. At euthanasia, the blood $\mathrm{Hb}$ was determined, and Fe analyses were performed in stool and liver samples using atomic absorption spectrophotometry. Cecal tissue was collected for histological and morphometric analysis. No significant differences were observed in the blood $\mathrm{Hb}$ or $\mathrm{Hb} \mathrm{Fe}$ pool between groups in either period. Iron overload led to a higher fecal Fe excretion, whereas the liver Fe was increased only after $12 \mathrm{wk}$ when compared with controls. After $4 \mathrm{wk}$, the consumption of Fe-overloaded diets resulted in changes in the mucosal architecture of the cecum, which were intensified after $12 \mathrm{wk}$. At this time, these changes were significantly correlated with the hepatic Fe content. These findings suggest that changes in the cecal mucosa may have occurred as a result of oxidative stress caused by excessive amounts of $\mathrm{Fe}$ in the intestinal lumen. The consequences of these effects on the intestinal absorption and its implications for liver Fe homeostasis should be considered in future studies.
\end{abstract}

Key Words diet, iron overload, liver, cecum, rats

Iron-deficiency anemia is still the most common nutritional problem worldwide (1). In Brazil, the mandatory fortification of corn and wheat flours with Fe and folic acid has been an important strategy for reducing the prevalence of Fe-deficiency anemia (2). However, it is important to evaluate the impacts of fortifying foods with Fe from another perspective. In this context, it is necessary to know and understand the risks and consequences of a possible dietary Fe overload, especially in individuals considered non-anemic, for whom the program would not apply (3-5).

Intestinal $\mathrm{Fe}$ absorption is tightly regulated by body $\mathrm{Fe}$ stores $(6,7)$ such that, under normal circumstances, systemic Fe overload would be unlikely to occur. However, excessive amounts of intraluminal Fe could increase the susceptibility of the intestinal epithelial cells to oxidative damage and inflammation, with impacts on mucosal barrier integrity and intestinal permeability $(8-12)$. For example, patients with hereditary hemochromatosis, a genetic disorder characterized by increased Fe absorp-

*To whom correspondence should be addressed.

E-mail: cecolli@usp.br

Abbreviations: CT, control group; Hb, hemoglobin; IO, iron overload. tion and tissue Fe accumulation, present more histological abnormalities in small and large intestine mucosa with inflammation features, such as increased number of lymphocytes and plasmocytes, villous blunting, and crypt distortion, in comparison with controls (12). Furthermore, histological scores based on morphological criteria are improved in rat models of colitis when dietary $\mathrm{Fe}$ is reduced, which implies that reducing the $\mathrm{Fe}$ supply could be a strategy for the treatment of inflammatory bowel disease (13).

In this study, we hypothesized that increased liver Fe levels due to dietary Fe overload may be associated with architectural changes in the cecal mucosa. Timedependent changes in the cecal crypt morphology were observed as a result of Fe overload, and they were significantly associated with increases in liver Fe contents despite unaltered blood $\mathrm{Hb}$ levels. The implications of these findings on intestinal health and especially on the systemic changes caused by excessive and chronic consumption of Fe in the diet should be carefully evaluated in future studies.

\section{MATERIALS AND METHODS}

Animals and experimental diets. The experimental protocol was approved by the Commission on Ethics in 
Animal Experiments of the Faculty of Pharmaceutical Sciences of the University of São Paulo (CEEA 88/2005 FCF-USP) according to the guidelines of the Brazilian College on Animal Experimentation. Weanling male Wistar rats (Rattus novergicus, var. albinus; $n=33$; initially weighing 46-52 g) were obtained from the colony of the Faculty of Pharmaceutical Sciences, University of São Paulo. All rats were housed in individual stainless steel wire mesh cages under a controlled temperature $\left(22^{\circ} \mathrm{C} \pm 2^{\circ} \mathrm{C}\right)$ with a 12 -h light-dark cycle (lights off from $8 \mathrm{PM}$ to $8 \mathrm{AM}$ ). The experimental semipurified diets were modified from the formulation proposed by the American Institute of Nutrition (AIN) for growth, pregnancy and lactational phases of rodents AIN-93G (14). Iron in the form of encapsulated ferrous sulfate $\left(\mathrm{FeSO}_{4} \cdot 7 \mathrm{H}_{2} \mathrm{O}\right.$; Fermavi Eletroquímica Ltda, São Paulo, Brazil) (15) was used in the mineral mixture formulation of the diets. The following factors were used for energy calculations: 4 calories per gram for carbohydrates and proteins, and 9 calories per gram for lipids.

Two experiments were performed. The animals were fed either Fe-adequate (control [CT] group) or Fe-overloaded (IO group) diets for $4 \mathrm{wk}$ (Fe contents, 50 and $413 \mathrm{mg} \mathrm{Fe} / \mathrm{kg}$ diet, respectively, as measured by atomic absorption spectrophotometry [AAS; AAnalyst 100, Perkin Elmer, Norwalk, CT]; $n=10$ for CT group and $n=9$ for IO group) and $12 \mathrm{wk}$ (Fe contents, 49 and $580 \mathrm{mg} \mathrm{Fe} / \mathrm{kg}$ diet, respectively; $n=7$ for each group). The animals were acclimatized for $5 \mathrm{~d}$ before starting the experiment. The food intake was determined daily, and the body weight was recorded every $3 \mathrm{~d}$. Food and demineralized water were offered ad libitum. The food efficiency was determined as the weight gain per gram of food intake at the end of each experimental period. Feces were quantitatively collected during the last $5 \mathrm{~d}$ of each experiment, pooled, and stored at $-20^{\circ} \mathrm{C}$.

Sampling procedures. At the end of the experimental periods, the rats were anesthetized with a $1: 1: 0.4: 1.6(\mathrm{v} / \mathrm{v} / \mathrm{v} / \mathrm{v})$ mixture of ketamine $(10 \mathrm{mg} /$ $\mathrm{kg}$; Vetaset, Fort Dodge, IA), xylazine $(25 \mathrm{mg} / \mathrm{kg}$; Virbaxil 2\%, Virbac, São Paulo, Brazil), acepromazine (2 mg/mL; Acepran 0.2\%, Univet S/A Indústria Veterinária, São Paulo, Brazil) and demineralized $\mathrm{H}_{2} \mathrm{O}$. After the anesthesia had caused unconsciousness, blood was withdrawn from the abdominal aorta for analysis of the Fe status parameters. The rats were then sacrificed by exsanguination under anesthesia. The liver was perfused through the subhepatic vein with a $\mathrm{NaCl}$ solution $(9 \mathrm{~g} / \mathrm{L})$ to drain blood out of the organ. The liver was excised, weighed and stored for further analysis. The cecum and its contents were removed, weighed, placed in a Petri dish with ice (16) and cut open along the small curvature. The cecal content $\mathrm{pH}$ was measured in situ by inserting an electrode (UP-25; Denver Instrument, Denver, CO) through the ileocecal junction, as described previously (17). Cecal tissue samples were collected and fixed in 10\% formaldehyde solution, stored in 70\% ethanol and further used for histological and morphometric analyses.

Blood hemoglobin and iron concentration in the diets, liver and stools. The blood Hb concentration was determined with a commercial kit (Ref 43, Labtest; Lagoa Santa, MG, Brazil) via the cyanide Hb method (18) and commercially available control material (Labtest). The $\mathrm{Hb} \mathrm{Fe}$ pool was calculated according to the following equation, assuming that $6.7 \%$ of body weight is blood and that $\mathrm{Hb}$ contains $0.335 \% \mathrm{Fe}(19)$ :

$\mathrm{Hb}$ Fe pool (mg)

$$
=\frac{\text { [body weight }(\mathrm{g}) \times \mathrm{Hb}(\mathrm{g} / \mathrm{L}) \times 6.7 \times 0.335]}{10,000}
$$

Iron concentrations were determined in the diets, liver and stools. Liver analyses were performed from the left lateral lobe of the liver. Dry feces $\left(105^{\circ} \mathrm{C}, 15 \mathrm{~h}\right)$ were milled, and the powdered samples were utilized for Fe analyses. Iron analyses were performed by AAS employing a hollow cathode lamp at $248.3 \mathrm{~nm}$ and slit of $0.2 \mathrm{~nm}$ after wet digestion $\left(\mathrm{HNO}_{3}: \mathrm{H}_{2} \mathrm{O}_{2}, 5: 1 ; \mathrm{v} / \mathrm{v}\right)$. The working standard solution was prepared with ferric chloride $\left(\mathrm{FeCl}_{3}\right)$ (Tritisol, Merck, Darmstadt, Germany). A defatted AIN-93G diet was employed as a secondary standard. Flasks and glassware were demineralized prior to all mineral analyses.

Cecal histology and morphometric analyses. For histological examination, the tissue-fixed fragments were processed and embedded in paraffin, and 5- $\mu \mathrm{m}$-thick cuts were obtained and stained with hematoxylin and eosin (H.E.). The intensity and composition of inflammatory infiltrate in the lamina propria and number of intraepithelial lymphocytes/100 colonocytes were examined independently by an experienced pathologist (L.R.M.S.), who was blinded to the identity of the animals. Cecal evaluation was graded as normal cecum (scored 0) or mild (scored 1), moderate (scored 2) or marked (scored 3) typhlitis based on following criteria: (0) five or fewer and scattered inflammatory mononuclear cells in the lamina propria between the crypts was graded as a normal cecum, (1) mildly increased number of inflammatory cells (mononuclear cells) at $40 \times$ in the lamina propria of the inter-cryptal region that did not disrupt normal perpendicular cryptal structure was graded as mild typhlitis, (2) numerous inflammatory cells (mononuclear cells) in the lamina propria, generally more than 5 cells that filled the inter-cryptal region and mildly increase separation of the crypts and may have altered the cryptal structure and 2-3 layers below the crypt line was graded as moderate typhlitis, (3) numerous inflammatory cells (mononuclear cells) that disrupted cryptal structure and filled the inter-cryptal region and generally extend more than 3 layers below the crypt and into the submucosa or invading cells in the crypt areas was graded as marked typhlitis. The presence of neutrophils was considered acute typhlitis even in few numbers; infiltrattion of eosinophils was considered as eosinophilic typhlitis when it was in predominant number in the lamina propria. Other parameters were crypt morphology, number of intraepithelial lymphocytes per 100 colonocytes, and number of mitoses in crypts. A crypt with more than 3 mitoses $/ 40 \times$ fields was considered as marked hyperplasia. 
Morphometric analysis included only crypts cut lengthwise that were used to measure the depth, with the crypts divided into arbitrary zones according to the lines of an ocular grid (Zeiss Integration Eyepiece I Kpl 8; Carl Zeiss, Hamburg, Germany) (20). These lines limited spaces or zones, which enabled us to calculate the number of spaces within each crypt. Each space was then taken as a standard measurement. At least 30 crypts per animal were used. For the determination of the number of bifurcating crypts, the crypts with an indentation at the base or presenting a longitudinal fission (one crypt mouth and two bases) were considered (21). The calculation was performed by determining the number of bifurcating crypts per microscopic field by the same criteria used to measure the depth of the crypts. To estimate the total number of crypts per microscopic field, obliquely sectioned crypts were included. At least 20 microscopic fields per animal were analyzed.

Statistical analysis. The statistical analysis was conducted with GraphPad Prism 5 for Windows, version 5.00 (GraphPad Software, San Diego, CA). Data are shown as the mean and standard deviation (SD) of the studied variable. The normality of the observations was verified through the Shapiro-Wilk test. The variable means of the groups were compared using the MannWhitney test. The correlation between parameters was assessed using Spearman's correlation test. Differences were considered significant if $p$ values were $<0.05$.

\section{RESULTS}

Total food and Fe intake, body weight gain, feed efficiency, hemoglobin, and liver and stool Fe concentrations

No significant differences in total food intake (week 4, $410 \mathrm{~g}$; week 12, 1,370 $\mathrm{g}$ for the CT group) or body weight gain (week 4, $163 \mathrm{~g}$; week 12, $293 \mathrm{~g}$ for the CT group) were observed between groups. These results were reflected in similar mean feed efficiencies between groups in both of the study periods. As expected, dietary Fe intake was significantly higher in IO animals than in controls (at weeks 4 and 12, $p<0.0001$; Fig. 1A). Dietary Fe overload led to higher fecal Fe excretion regardless of the period studied ( $p<0.0001$; Fig. 1B). Interestingly, the difference between the mean values of the Fe content excreted in feces per day between the IO and CT groups (in the last $5 \mathrm{~d}$ of fecal collection) decreased by $6 \mathrm{mg}$ from week 4 to week 12 (from 11.4 to $5.0 \mathrm{mg}$, respectively). However, the blood $\mathrm{Hb}$ and $\mathrm{Hb}$ Fe pools were not different between groups (Fig. 1C). By contrast, although the relative liver weight was unaffected at both time points (week $4,3.9 \mathrm{~g} / 100 \mathrm{~g}$ body weight; week $12,4.3 \mathrm{~g} / 100 \mathrm{~g}$ body weight, for the CT group), the liver Fe concentrations were significantly increased as a result of high Fe intake only at week 12 (week 4, $p=0.29$; week 12, $p<0.001$; Fig. 1D), an increment of approximately $3.4 \mathrm{mg}$ Fe in the liver from week 4 to week 12 (from 0.5 to $3.9 \mathrm{mg}$, respectively).

Cecal weight, $\mathrm{pH}$, mucosal histology and morphometric analysis

Dietary Fe overload did not influence the total cecum weight or the $\mathrm{pH}$ of the cecum contents during the early (week 4, $1.3 \mathrm{~g} / 100 \mathrm{~g}$ body weight and $\mathrm{pH}$ value 6.5 , for
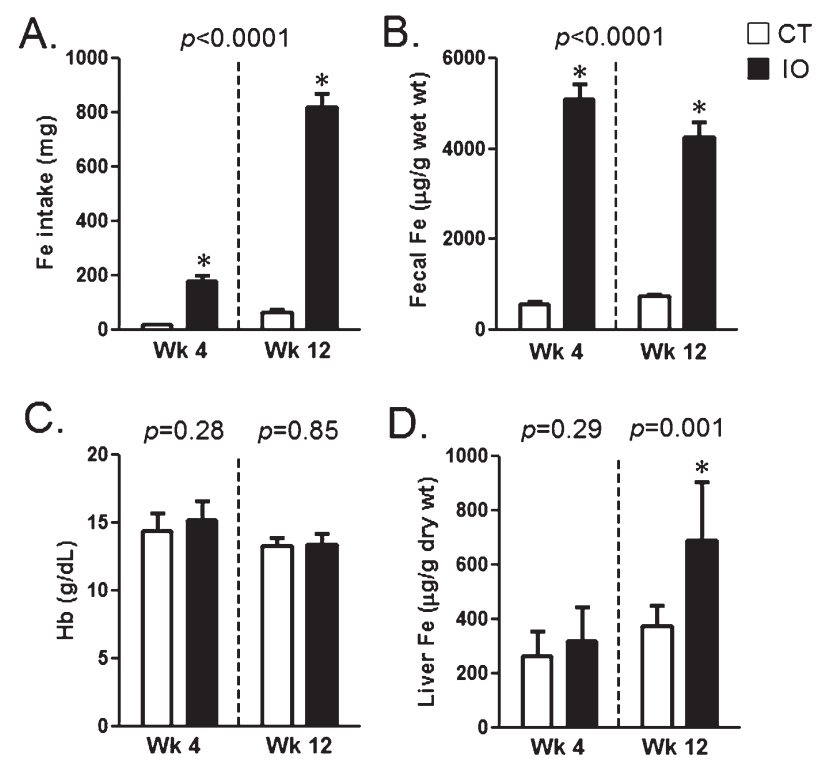

Fig. 1. Dietary Fe overload led to liver Fe accumulation without affecting blood $\mathrm{Hb}$ levels. Total Fe intake (A), fecal (B), blood $\mathrm{Hb}(\mathrm{C})$ and liver (D) Fe concentrations of rats after 4 and $12 \mathrm{wk}$ of feeding Fe-adequate (CT group) and Fe-overloaded (IO group) diets. The results are expressed as the mean \pm standard deviation (SD) (week 4: $n=10$ for the CT group and $n=9$ for the IO group; week 12: $n=7$ for the CT group and $n=7$ for the IO group). The differences between the means of the groups were assessed through the Mann-Whitney test. All tests were performed considering a significance level of $5 \%$.

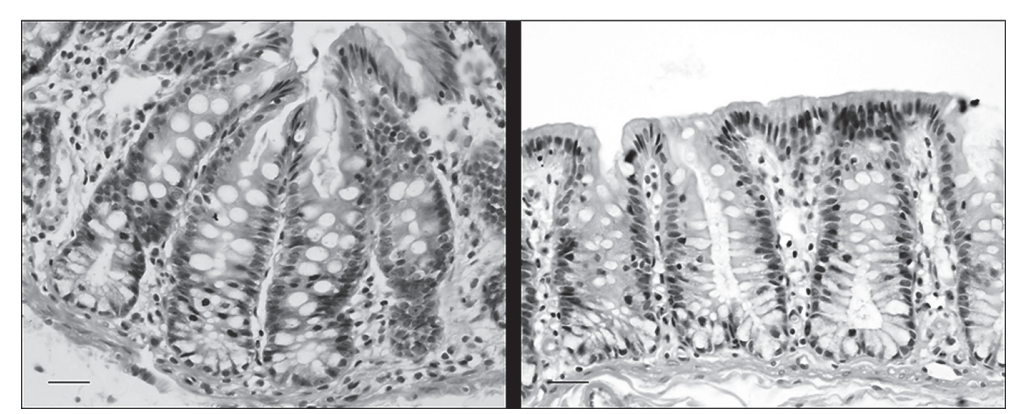

Fig. 2. Cecum histological analysis. Cecal mucosa of Fe-overloaded animals after $12 \mathrm{wk}$ showing an increased number of mitoses cells in the cryptal area (left) and an increased number of bifurcating crypts (right). H.E., Bar=25 $\mu \mathrm{m}$. 
A

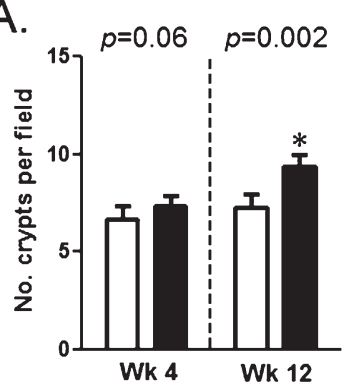

B.

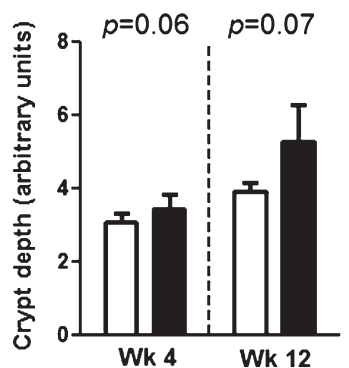

C.

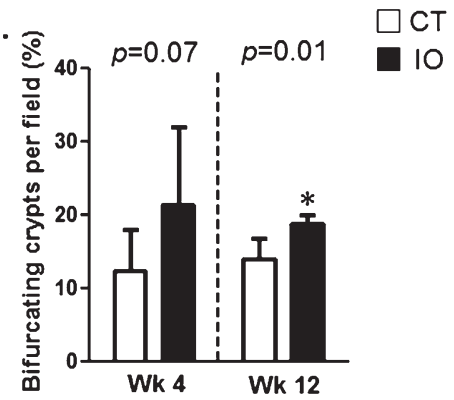

Fig. 3. Time-dependent changes in crypt morphology in the cecum as a result of consumption of Fe-overloaded diets. Number of crypts (A), crypt depth (B) and bifurcating crypts (C) of rats after 4 and 12 wk feeding Fe-adequate (CT group) and Fe-overloaded (IO group) diets. The results are expressed as the mean \pm standard deviation (SD) (week 4: $n=10$ for the CT group and $n=9$ for the IO group; week 12: $n=7$ for the CT group and $n=7$ for the IO group). The differences between the means of the groups were assessed through the Mann-Whitney test. All tests were performed considering a significance level of $5 \%$.
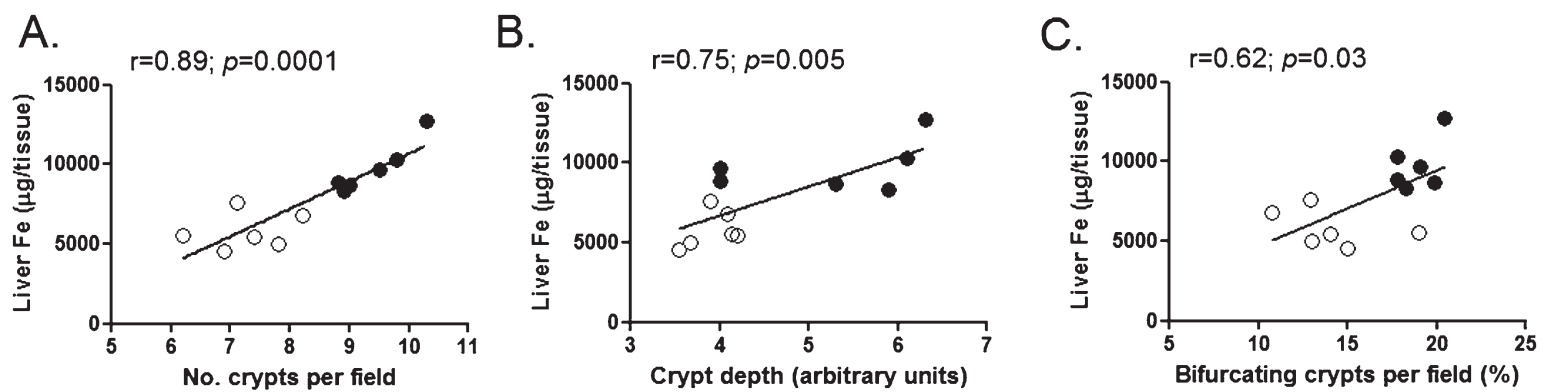

Fig. 4. Liver Fe contents positively correlate with crypt morphological parameters of rats after 12 wk feeding Fe-adequate (CT group) and Fe-overloaded (IO group) diets. Correlations between liver Fe contents and number of crypts (A), crypt depth (B) and bifurcating crypts $(\mathrm{C})(p<0.05)$. Insets correspond to Spearman's $r$ correlations and corresponding $p$ values.

the CT group, respectively) or late (week $12,0.9 \mathrm{~g} / 100 \mathrm{~g}$ body weight and $\mathrm{pH}$ value 7.0 , for the CT group, respectively) periods. By contrast, although histological analysis did not reveal an inflammatory process in the cecal mucosa of either studied period, IO cecum at week 12 presented marked cryptal hyperplasia featured by an increased number of mitoses and nuclear overlap in the proliferative region of cryptal area (Fig. 2). According to morphometric analysis there was a trend for an increased number of crypts $(p=0.06)$ and crypt depth $(p=0.06)$ interpreted as a result of excess dietary Fe at week 4 of the experimental period. At week 12, these results were further intensified (number of crypts; $p=0.002$ ) or maintained (crypt depth; $p=0.07$ ) (Fig. 3A and B). At this point, these effects occurred concomitantly with a greater number of bifurcating crypts (in fission) in IO rats when compared to controls $(p=0.01$; Fig. 2 and Fig. 3C) which also was corroborated with cryptal hyperplasia described in H.E. analyses (Fig. 2). In addition, significant correlations were found between liver $\mathrm{Fe}$ contents and (a) number of crypts $(r=0.89$, $p=0.0001)$; (b) crypt depth $(r=0.75, p=0.005)$; and (c) bifurcating crypts $(r=0.62, p=0.03)$ (Fig. $4 \mathrm{~A}-\mathrm{C})$ after $12 \mathrm{wk}$ of the experiment.

\section{DISCUSSION}

Iron supplementation, food fortification and/or dietary management have been considered the main strategies for controlling Fe-deficiency anemia. The objective of these strategies is to increase the supply of available $\mathrm{Fe}$ for $\mathrm{Hb}$ synthesis for a specific period of time. Apart from the enhanced risks of Fe overload as a result of higher Fe absorption in genetically susceptible individuals, the long-term effects of highly bioavailable $\mathrm{Fe}$ (as Fe supplements or heme Fe) and Fe-fortified food consumption in non-anemic individuals (to whom $\mathrm{Fe}$ fortification would not apply) have been discussed (3-5). This aspect is particularly relevant considering the association of elevated Fe stores with aging-related diseases, ranging from cancer to Alzheimer's, as well as other chronic diseases such as obesity, diabetes and cardiovascular diseases (22-24).

In Fe-overload situations, the liver increases its capacity for Fe storage and becomes susceptible to tissue damage because Fe is a catalyst in the Haber-Weiss reaction, which participates in the formation of reactive oxygen species $(8,11,22)$. In fact, the present results show that hepatic Fe levels increase proportionally to dietary intake and that this increase was significant after $12 \mathrm{wk}$. We previously observed hepatic Fe accumulation in rats fed up to 40 times the recommended levels after $12 \mathrm{wk}$, and this effect was associated with increased hepatocyte apoptosis (Unpublished results). In fact, Fe-generated reactive oxygen species have been related to lipid peroxidation, increased mitochondrial membrane permeability, apoptosis and even necrosis in hepatic cells $(8,10$, 


\section{1, 23, 25).}

Chronic dietary Fe overload can also alter intestinal homeostasis by a mechanism involving changes in gut microbiota composition, oxidative damage and inflammation $(8-10,13,26,27)$. Considering that fractional intestinal Fe absorption is frequently low, with minor variations depending on the food matrix or the physiological state, unabsorbed $\mathrm{Fe}$ in the small intestine reaches the large intestine in an "available" form within the range required for significant free radical production $(8-10)$. These effects would impact (a) the mucosal barrier integrity by affecting the cellular dynamics and permeability in intestinal mucosa, as well as (b) the microbial composition and metabolic activity by stimulating the growth and pathogenicity of intestinal bacteria $(9$, 26-28).

The present findings demonstrated that dietary $\mathrm{Fe}$ overload induces morphological changes in the cecal crypts (increased mitoses in the cryptal area, crypt number, length and fission), which were intensified after $12 \mathrm{wk}$. Interestingly, only at this time point were these effects significantly associated with liver Fe stores, suggesting that increased liver Fe accumulation could have occurred as morphological changes took place in the intestine. Crypt hyperplasia in the large intestine has been shown in rodent studies after Fe supplementation, such as inorganic salts (9) or heme Fe (27), and could occur as a compensatory response to injury induced by excess $\mathrm{Fe}$ in the intestinal lumen (27). Although we used a dietary Fe loading at approximately 10 times the recommended levels for rodents (14), other authors have reported changes in crypt cellularity and lipid peroxidation with milder dietary Fe contents (approximately $100 \mathrm{mg} \mathrm{Fe} / \mathrm{kg}$ diet) but with longer experiments (>6 mo) (9, 10). Moreover, to our knowledge, there are no studies describing cryptal hyperplasia and an increased number of crypts in the bifurcation process as a result of excess Fe in the diet. It has been proposed that crypt cell proliferation and crypt fission are complementary mechanisms for increasing tissue mass (29). Small indentations are observed in the base of a crypt, which then ascend longitudinally and proceed until there are two separate crypts (30), a process thought to be related to the expansion of the crypt stem cell population (31). This process is increased in postnatal development, during recovery of the intestine from injury and in crypts isolated from adenomas and hyperplastic polyps (31-33).

On the other hand, systemic Fe dysregulation can influence the inflammatory response in the gut by affecting circulating hepcidin levels (34). For example, increased hepatic hepcidin expression has been observed in rat models of gut inflammation (34). Hepcidin binds to membrane-associated ferroportin in intestinal cells (and other cell types), inhibiting cellular Fe release to circulation (35). Down-regulation of ferroportin leads to an accumulation of intracellular Fe, increased ferritin (the cell's Fe storage protein) expression, and increased susceptibility to oxidative stress $(35,36)$. Thus, Fe overload, through its effects on crypt cell proliferation and microbiota, and an increased labile Fe pool mediated by hepcidin's action on the intestinal cells might act additively to enhance the intestinal damage.

In summary, chronic dietary Fe overload led to liver Fe accumulation, an effect that was associated with changes in crypt architecture in the large intestinal mucosa. We consider that these changes may occur as a result of a change in microbiota and/or oxidative stress caused by higher amounts of $\mathrm{Fe}$ in the gut lumen. Whether these changes in the intestine could be ameliorated with dietary supplementation of antioxidants or anti-inflammatory bioactive compounds is an issue for further research. Thus, the implications of the present findings on the intestinal environment, and especially on the systemic changes caused by the chronic consumption of excess $\mathrm{Fe}$, should be carefully evaluated in future studies.

\section{Acknowledgments}

The authors thank Dr. Eliana Parisi Alvares and Mr. Cruz Alberto Mendoza Rigonatti for their collaboration in the histological analysis; Ms. Tatiana Garofalo Quintal for technical assistance; and Fundação de Amparo à Pesquisa do Estado de São Paulo (research project 2006/01735-0) for supporting the research and Conselho Nacional de Desenvolvimento Científico e Tecnológico (CNPq) for the fellowships awarded to Alexandre R. Lobo and Maria Lucia Cocato. This study was also supported by Coordenação de Aperfeiçoamento de Pessoal de Nível Superior (CAPES).

\section{Conflicts of interest}

There are no conflicts of financial, professional, or personal interests for any of the authors. Alexandre Rodrigues Lobo: study concept and design; acquisition, analysis and interpretation of data. Maria Lucia Cocato: study concept and design, acquisition and analysis of data. Lilian Rose Marques de Sá: acquisition, analysis and interpretation of data. Célia Colli: study concept and design; acquisition, analysis and interpretation of data; obtained funding.

\section{REFERENCES}

1) Benoist B, McLean E, Egli I, Cogswell M. 2008. Worldwide Prevalence of Anaemia 1993-2005. World Health Organization, Geneva, Switzerland.

2) Agência Nacional de Vigilância Sanitária. Legislação. Legislação especifica por área de assunto. Regulamentos técnicos por assunto: F. Farinha de trigo e/ou milho fortificados com ferro. Resolução RDC n.344, de 13 de Dezembro de 2002. [Online]. Available: http://portal. anvisa.gov.br [accessed December 8, 2013].

3) Whittaker P, Chanderbhan RF. 2001. Effect of increasing iron supplementation on blood lipids in rats. $\mathrm{Br} J$ Nutr 86: 587-592.

4) Brandsch C, Ringseis R, Eder K. 2002. High dietary iron concentrations enhance the formation of cholesterol oxidation products in the liver of adult rats fed salmon oil with minimal effects on antioxidant status. J Nutr 132: 2263-2269.

5) Pouraram H, Elmadfa I, Dorosty AR, Abtahi M, Neyes- 
tani TR, Sadeghian S. 2012. Long-term consequences of iron-fortified flour consumption in nonanemic men. Ann Nutr Metab 60: 115-121.

6) Frazer DM, Anderson GJ. 2005. Iron imports. I. Intestinal iron absorption and its regulation. Am J Physiol 289: G631-G635.

7) Schümann K, Ettle T, Szegner B, Elsenhans B, Solomons NW. 2007. On risks and benefits of iron supplementation recommendations for iron intake revisited. J Trace Element Med Biol 21: 147-168.

8) Rimbach G, Markant A, Most E, Pallauf J. 1997. Liver and colon oxidant status in growing rats fed increasing levels of dietary iron. J Trace Element Med Biol 11: 99-104.

9) Lund EK, Wharf SG, Fairweather-Tait SJ, Johnson IT. 1998. Increases in the concentrations of available iron in response to dietary iron supplementation are associated with change in crypt cell proliferation in rat large intestine. J Nutr 128: 175-179.

10) Lund EK, Fairweather-Tait SJ, Wharf SG, Johnson IT. 2001. Chronic exposure to high levels of dietary iron fortification increases lipid peroxidation in the mucosa of the rat large intestine. J Nutr 131: 2928-2931.

11) Galaris D, Pantopoulos K. 2008. Oxidative stress and iron homeostasis: mechanistic and health aspects. Crit Rev Clin Lab Sci 45: 1-23.

12) Zhou W-X, Wu X-R, Bennett AE, Shen B. 2014. Endoscopic and histologic abnormalities of gastrointestinal tract in patients with hereditary hemochromatosis. J Clin Gastroenterol 48: 336-342.

13) Uritski R, Barshack I, Bilkis I, Ghebremeskel K, Reifen R. 2004. Dietary iron affects inflammatory status in a rat model of colitis. J Nutr 134: 2251-2255.

14) Reeves PG, Nielsen FH, Fahey Jr GC. 1993. AIN-93 Purified diets for laboratory rodents: final report of the American Institute of Nutrition ad hoc writing comittee on reformulation of the AIN-76A rodent diet. J Nutr 123: 1939-1951.

15) Cocato ML, Ré MI, Trindade Neto MA, Chiebao HP, Colli C. 2007. Avaliação por métodos in vitro e in vivo da biodisponibilidade de sulfato ferroso microencapsulado. Braz J Nutr 20: 239-247.

16) Lu ZX, Gibson PR, Muir JG, Fielding M, O’Dea K. 2000. Arabinoxylan fiber from a by-product of wheat flour processing behaves physiologically like a soluble, fermentable fiber in the large bowel of rats. J Nutr 130: 1984-1990.

17) Lobo AR, Cocato ML, Borelli P, Gaievski EHS, Crisma AR, Nakajima K, Nakano EY, Colli C. 2011. Iron bioavailability from ferric pyrophosphate in rats fed with fructancontaining yacon (Smallanthus sonchifolius) flour. Food Chem 126: 885-891.

18) Drabkin DL, Austin JH. 1935. Spectrophotometric studies II. Preparations from washed blood cells: nitric oxide hemoglobin and sulphemoglobin. J Biol Chem 112: $51-65$.

19) Mahoney AW, Van Orden CC, Hendricks DG. 1974. Efficiency of converting food iron into haemoglobin by the anaemic rat. Nutr Metabol 17: 223-230.

20) Lobo AR, Colli C, Alvares EP, Filisetti TMCC. 2007. Effects of fructans-containing yacon (Smallanthus sonchifolius Poepp \& Endl.) flour on caecum mucosal morphometry, calcium and magnesium balance, and bone calcium retention in growing rats. Br J Nutr 97: 776-785.

21) Maskens AP. 1978. Histogenesis of colon glands during postnatal growth. Acta Anat 100: 17-26.

22) Xu J, Knutson MD, Carter CS, Leeuwenburgh C. 2008. Iron accumulation with age, oxidative stress and functional decline. PLoS ONE 3: e2865, doi: 10.1371/ journal.pone.0002865

23) Orr JS, Kennedy A, Anderson-Baucum EK, Webb CD, Fordahl SC, Erikson KM, Zhang Y, Etzerodt A, Moestrup SK, Hasty AH. 2014. Obesity alters adipose tissue macrophage iron content and tissue iron distribution. Diabetes 63: 421-432.

24) Qi L, Van Dam RM, Rexrode K, Hu FB. 2007. Heme iron from diet as a risk factor for coronary heart disease in women with type 2 diabetes. Diabetes Care 30: 101-106.

25) Liu D, He H, Yin D, Que A, Tang L, Liao Z, Huang Q, He M. 2013. Mechanism of chronic dietary iron overload-induced liver damage in mice. Mol Med Rep 7: 1173-1179.

26) Zimmermann MB, Chassard C, Rohner F, N'goran EK, Nindjin C, Dostal A, Utzinger J, Ghattas H, Lacroix C, Hurrell RF. 2010. The effects of iron fortification on the gut microbiota in African children: a randomized controlled trial in Côte d'Ivoire. Am J Clin Nutr 92: 1406-1415.

27) IJssennagger N, Derrien M, van Doorn GM, Rijnierse A, van den Bogert B, Müller M, Dekker J, Kleerebezem M, van der Meer R. 2012. Dietary heme alters microbiota and mucosa of mouse colon without functional changes in host-microbe cross-talk. PLoS ONE 7: e49868, doi: 10.1371/journal.pone.0049868

28) Dostal A, Chassard C, Hilty FM, Zimmermann MB, Jaeggi T, Rossi S, Lacroix C. 2012. Iron depletion and repletion with ferrous sulfate or electrolytic iron modifies the composition and metabolic activity of the gut microbiota in rats. J Nutr 142: 1-7.

29) Berlanga-Acosta J, Playford RJ, Mandir N, Goodlad RA. 2001. Gastrointestinal cell proliferation and crypt fission are separate but complementary means of increasing tissue mass following infusion of epidermal growth factor in rats. Gut 48: 803-807.

30) Totafurno J, Bjerknes M, Cheng H. 1987. The crypt cycle. Crypt and villus production in the adult intestinal epithelium. Biophys J 52: 279-294.

31) Bjerknes M, Cheng H. 2005. Gastrointestinal stem cells. II. Intestinal stem cells. Am J Physiol 289: G381-G387.

32) Cheng L, Araki K, Furuya, Matsuoka T, Mashima K, Kobayashi M, Matsuura K. 2000. Morphological study of the regeneration mechanism of acetic acidinjured colon crypts in the rat. Med Electron Microsc 33: 165-171.

33) Mandir N, Englyst H, Goodlad RA. 2008. Resistant carbohydrates stimulate cell proliferation and crypt fission in wild-type mice and in the $A P C^{\mathrm{Min} /+}$ mouse model of intestinal cancer, associated with enhanced polyp development. Br J Nutr 100: 711-721.

34) Cherayil BJ, Ellenbogen S, Shanmugan NN. 2011. Iron and intestinal immunity. Curr Opin Gastroenterol 27: 523-528.

35) Nemeth E, Tuttle MS, Powelson J, Vaughn MB, Donovan A, Ward DM, Ganz T, Kaplan J. 2004. Hepcidin regulates cellular iron efflux by binding to ferroportin and inducing its internalization. Science 306: 2090-2093.

36) Cairo G, Tacchini L, Pogliaghi G. 1995. Induction of ferritin synthesis by oxidative stress. Transcriptional and post-transcriptional regulation by expansion of the "free" iron pool. J Biol Chem 270: 700-703. 